the pulse was small and feeble, and she had a constant feeling of weariness and prostration of strength. She had been for some months under medical treatment with. out benefit. She visited Cheltenharn in the course of the last summer, and consulted some of the most eminent medical men there with no better result. Returning home in the autumn, she again came under my care, and having read in The LANceT an account of Dr. Elliotson's success in the treatment of similar affections by creosote. I tried that remedy, mixing six drops of it in a little mucilage, with six ounces of water. The patient took but two large spoonfuls of this mixture, when a remarkable change took place in every respect for,the better. She remained without sickness a whole day and night, which had not been the case any time for six months previous. Her features looked more natural, the headache and dimness of sight disappeared, the catamenia shortly afterwards occurred in a more natural and copious flow, and she appeared as if cured by magic, so sudden and decided was the effect; but being of an irresolute mind, I could not prevail upon her to continue the medicine, on account of its nauseous flavour. She had taken but one dose, and in a few days aiter enjoying her comfortable change, she began to experience a return of the symptoms; I then prevailed upon her to take a pill twice a day, containing one drop of creosote in two or three grains of aromatic confection. She continued this for a few days, and remained afterwards perfectly well.

Cass 2. - The next case occurred in the person of an infant, about eleven inontis oll; the sickness continued daily for a month, and resisteri all means employed to subdue it. This, like the last, seemed to consist in a suspension of the process of digestion, as the mother informed me that rice, given to the child for dinner at two o'clock p.m., was rejected the next moming from the stominch, unchanged in any respect. Indeed, this was the case with all the food the child took. It was rejected, frequently many hours afterwards, unaltered. The consequence was, great prostration of strength, with flaccidity of the muscles, pallid countenance, \&c. One drop of creosote, in an ounce and a half mixture, was administered, giving one teaspoonful three times a day with the completest success. The infant perfectly recovered, and needed no more medicine.

Remarks-I think thesc cases corroborative of the remarks of the learned professor of University College on the powers of creosote, and I am the more induced to transmit them for publication, seeing that some of your correspondents manifest a criticising disposition towards the lecturer. One declares that he has not read "his book," another" that he does not fit his
" case," so that if the Doctor's views and practice do not exactly correspond with those of all the carping critics who may exist from John O'Groat's to the Land's End in Cornwall, judgment must be pronounced against him. For myself $I$ am content to know that the learned Doctor is engaged diligently in reading the great book of nature, and own myseif indebted for many valuable hints, derived from the perusal of his talented, judicious, and highly practical clinical lectures, as I have found them reported in the pages of THE LANCET.

\section{CAsE OF}

\section{FUNGUS MEDULLARIS}

\author{
IN THE
}

\section{CAVITY OF THE PELVIS,}

\section{By Julres Wolfy, M.D., Dublin.}

A. P., 16 years of age, and of a slender habit, had, except during some diseases in his childhood, been perfectly healthy, up to the period at which the affection about to be described made its appearance. When 15 years of age, he begen to support his poor parents by dealing in various small articles, which he carried in a basket, the edge of which, as he walked, always pressed or struck against the upper part of the femur. One day he perceived on the inner side of the right thigh, abont two and a half inches below Poupart's ligament, a swelling of about the size of a hazel nut, which increaseil by degrees and impeded the motion of the linib. He applied to a surgeon, who ordered him to rub it with mercurial ointment, and to apply cataplasms; but under the use of these means the swelling in. creased.

In the month of February, 1834, he applied to me in Hanover, where I was then practising. I found the swelling of about the size of a duck's egg, very hard, uneven, immoveable, and insersible to the touch, The patient was in other respects very well, except that the swelling caused a feeling of tightness over the femur when walking, and, consequently, impeded his gait.

It could not be an inguinal or a fenoral hernia, because the swelling had an irregular shape, was hard, uneven, and immoveable, and its site did not oorrespond with any of the apertures through which herniz make their appearance.

It could not be a bubo, because the swell. ing was too far below the inguinal glands. It had lasted already sever months, and the skin which covered it presented its natural colour.

I had no reason to suspect the existence 
of psoas-abscess, because the symptoms which precede and attend such an affection were not present, and no fuctuation was perceived.

I did not apprehend it to be fungous medulla, because the manner of its commencement and its course seemed to contradict the supposition.

I ordered the patient to rub the tumour with a mixture of mercurial ointment and iodine, and to employ, internally, Plummer's powder - (Hydrarg. Chlorat. mit.; Stib. Sulphur. Aurant.) This treatment effected no improvement; but a few weeks after I could move the swelling under the skin from one side to the other.

The patient having requested me to de. liver him from the inconvenience under which he was labouring, I proposed an operation, as the surest and puickest means of getting rid of it. I expected that after having first made a longitudinal incision, and then detached the skin and fascia lata which covered the swelling, the remaining adhesions of the morbid mass could easily be detached with the fingers or the shaft of the scalpel.

Operation.-I performed the operation in the presence of two surgeons, Dr. Henniger and Mr. Lange. After 1 had cut through the integuments and fascia lata, a convolution of dark-blue vessels, and a cartilaginous mass, closely intermixed with each other, were forced out of the wound. They wert enclosed in a white, thick, tendinous membrane, and felt bard to the touch. I intro. duced a dissecting hook into the morbid mass, with which I drew it forth, and tried to separate the adhesions with the fingers and knife, by which means it came more fully in to view. Further examination with the finger showed that the mass had more extensive attachments than was at first apprehended, that it went both deeper between the muscles, and higher towards Poupart's ligament. I enlarged the incisiont in the skin, and the morbid mass, which was firmly adberent to the muscles, was, with great care, separated, and the muscles were thus laid perfectly bare.

To my great alarm $\mathbf{I}$ found now that the morbid mass passed below Poupart's ligament, into the abdomen, and could not be drawn forth, nor could I introduce my finger, to separate the adhesions. I had thus got into a difficulty, which, however, I endeavoured to coriceal from the many pergons who were present at the operation, until, after more accurately examining the wound with my finger, and reflecting a few moments, I came to the resolution of making an incision through the integuments, above Poupart's ligament, in such a manner as is practised when we wish to take up the common iliac artery. Through this incision, which was about two or two and a half inches long, I introduced the first and second finger of my left hand, under the sac of the peritoneum, to the psoas muscle. Here I discovered a soft morbid mass, which covered a part of this muscle, and which could easily be separated from it by the fingers. After this was done, I found no difficulty in separating that morbid portion which adhered to Poupart's ligament, and drawing forth the mass which I had just before separated with my fingers in the abdomen. The part thus separated was of the weight of nine and a half ounces.

Morbid appearances. - On examination of the morbid structure, it was found that the part which had been situated out of the abdomen, and which had felt so hard and uneven, consisted of dark-blue dilated and contorted vessels, mixed up with a cartila. ginous mass, and little grannles of fat, all of which were enclosed in a thick white fibrous tunic. The part situated in the abdomen was soft, like the substance of the brain, attached together, of a gray-white colour, intermingled with a great number of minute red vessels, and enclosed in a thin white nembrane. In short, it had all the charac. ters of medullary sarcoma.

Whether the disease took its origin internally or externally it might be difficult to decide positively. To me however it seems most probable, that the fungous mass in the cavity of the pelvis was of a later date than that situated on: he thigh, because the patient had never complained of general indisposition, and any inconvenience he had suffered was limited to the external swelling alone.

Progress.-The wound above Poupart's ligament was soon healed up by being simply brought together with emplast. adhæsiv., whilst the larger wound below Poupart's ligament was dressed with simple ointment. The patient was put to hed, and an appropriate diet was ordered. Except a very slight degree of fever, which appeared in the evening of the 3rd day after the operation, the patient went on very well. His appetite and sleep were good, and the bowels regular. The wound looked well, and suppurated but little. A few days after, he was able to be out of bed, and could walk up and down the room. In the fifth week he went out of doors, without, how. ever, returning to his former occupation. The wound gradually became sinaller, and gave issue to but little matter, and that of a good quality.

In the seventh or eighth week after the operation, one afternoon, a sudden bleeding from the wound took place, without any known cause, and to such a considerable amount that the patient was almost ex. hausted. Cold applications were used, and the bleeding was thus checked. I was un. able to discover the source of this hemor. rhage. It returned frequently, but in smaller quantities, and wan always checked by the 
application of cold water. After a few weeks the patient got a cachectic look, became low-spirited, and lost his appetite. He had, during the day, at irregular intervals, horripilations, and, towards evening, a degree of low fever. The wound assumed an unfayourable aspect, and ceased to secrete healthy matter, but poured forth, in place of it, serum in great quaritities. Out of the bottom of the wound a brain-like mass again shot forth. Light nourishing diet was now ordered, together with the decoction of the cinchona bark, with sulphuric acid, whilst, externally, fomentations, with the same decoction, and alum, were given. The patient apparently, rallied. His appetite returned. In the evening the fever gradually left him, the wound had assumed a somewhat better appearance, the morbid substance was secreted in large quantities, and the secretion of the serous fluid decreased.

The patient continued to be in this favourable state for a few weeks, and the wound appeared becoming less. But he had, now and then, slight fits of intermittent fever, of the tertian type, which was endemic in the village in which he lived; but this was soon checked by using the sulphate of quinine.

In this state the patient remained for a - few months. His strength apparently increased, the wound became smaller, and secreted but little of the fluid mentioned. The cachectic appearance of the patient, however, did not leave him, though he said that he felt very well. The wound, which was now about the size of half-a-crown, be. came again of a whitely appearance, and anew secreted a very considerable quantity of the above-mentioned fluid, so that the patient was constantly wet with it. He grew thin, got evening-fever, and had a dry cough, lost his appetite, and was obliged once more to be constantly confined to his bed. This excessive secretion lasted for six or seven weeks, until at length, by the steady use of external and internal tonic and astringent remedies, it, to a certain degree, diminished. The patient, however, was visibly wasting away; the dry cough was now very teasing, and the bark no longer agreed with him. I ordered Decoct. Lich. Island., Pulv. Sulph. Aurant., Antim., et Extr. Cicut., which diminished the cough. Soon after, however, colliquative perspiration and diarrhoea made their appearance, together with expec. toration of matter, and gangræen. decubit., on the os sacrum, and aphthæ in the mouth, so that the patient was unable to swallow anything

In the thirteenth month after the operation, death ensued, the patient being in a state of extreme emaciation. The examination of the body was not permitted.

34, Nassau-street;

Dublin, Jan. 11th, 1836.

\section{PHENOMENON OF THE PULSE.}

\section{To the Editor of THE LANCET.}

SrR,-The following is transmitted for insertion in a corner of your periodical :-

Staff-assistant surgeon Dr. Hopkins, having occasion to be absent from town for twenty-four hours, requested me to take medical charge of the detachments, stationed in St.John's, for him until his return. On doing so, he stated that he had been called in the morning to see one of the sergeant's wives, who appeared to be labouring under an áttack of modified epilepsy. He had ordered an aperient and an injection. About four hours after (at two p.m.) I visited the patient, and found her presenting the following amongst other symptoms :Complete coma; the pupils dilated; pulse full, soft, and between 80 and 90 . On inquiry, I learnt that she had complained, on the previous day, of headache, and had, on the same evening, got drunk, being accus tomed to tippling. I ordered fifteen grains of calomel, immediately to be followed by a solution of sulphate of magnesia ( $3 j$ to 5 viij of water, 亏3ij. $0 \mathrm{~m} .6$. post. calomelan), wet cloths to the head, and fomentations, and bottles filled with hot water, to be applied to the soles of the feet, the calves of the legs, \&c. While I was standing by her side, with the finger on the pulse, she was seized with a sub-epileptic fit, experiencing twitches of the muscles of the face, of the superior and inferior extremities, \&c. The pulse, from being full and soft, became a mere thread, and quicker and harder. I was struck with the phenomenon, as I could not bring to my recollection having ever read of such an occurrence during epilepsy, and on reference to my books, 1 have not been able to find the circumstance recorded. I have conversed with most of my medical brethren here, some of whom have retired from practice for ten, fifteen, or twenty years, but not one of them has ever met with such an occurrence. It is from this circumstance that I have ventured to request the insertion of some particulars of the case. One of two causes must have occasioned the diminution of the pulse's volume, either a muscular "vis insita," partaking of the influence of the epileptic seizure, or pressure of the muscles of the arm and fore-arm. But if the latter was efficient, would not the artery, where it is superficial, at the wrist, rather have increased in volume than otherwise? For if we fill a flexible tube with a fluid, and apply a compressing force to two-thirds of its extent, the remaining third will increase in volume, as a matter of course, if the tube be dilatable. I have always been disinclined to allow the claim of muscularity of the arteries; but this case has, 1 confess, a little staggered my creed. The woman did 